\title{
USING GIS IN EMERGENCY MANAGEMENT
}

\section{Miloš Milenković1, Dalibor Kekić}

\author{
${ }^{1}$ Ministry of Interior, \\ Sector for Emergency Situations, \\ Omladinskih brigada 31, \\ Belgrade, Serbia \\ ${ }^{2}$ Academy of Criminalistic and Police \\ Studies, \\ Cara Dušana 196, Zemun, Serbia
}

\begin{abstract}
:
Complete, easy-to-use and timely information about geographic objects and factors and their influence is very important for making the right decisions. By the development and introduction of technologies as geographic information systems (GIS technology), this process should be much easier than before. Emergency management basically includes four phases, namely preparedness, mitigation, response and recovery. In all mentioned phases, GIS could be used because emergency management actions are based on the analysis of information. A considerable amount of information, which is used in emergency management, has spatial characteristics and can be shown on maps. Also, when some information is mapped and data is linked to the map, decision makers in all phases of emergency management have a powerful tool for making the appropriate decision. Emergency situations nowadays occur more often than before and emergency management personnel have critical tasks to protect people's lives, their property and environmental values. In solving these tasks, GIS will facilitate their work and raise public safety before, during and after some natural or other disasters. Institutions responsible for emergency management are aware of those facts and make considerable effort to implement GIS in their work.
\end{abstract}

Key words:

GIS, emergency management, preparedness, response, recovery.

\section{INTRODUCTION}

GIS stands for "Geographic Information System". GIS application is used to deal with spatial information on a computer. Most precisely it is the spatial representation, capture, storage, retrieval, analysis, display of information (attribute data) that is positioned to correspond to the same $\mathrm{X}, \mathrm{Y}$ (and Z, if needed) coordinates throughout the various map layers (European emergency number association, 2015). At same time, GIS uses words, numbers and other data from database and makes correlation with locations with the aim to show that on maps. It is a tool for help to responsible people who have to take right decision. It is worth mentioning that GIS cannot make decision alone.

GIS is not only a program for representing maps. It is far beyond that because GIS adds useful information for parts of maps. By enhanced maps, decision makers have great possibilities to analyze locations, their relations, the fastest way to arrive at the particular location or similar. These possibilities are very important in many areas, especially in police, military jobs and other related to safety of citizens. Emergency management
Correspondence:

e-mail:

milos10jul@gmail.com 
is very important for safety and security and GIS is one very useful tool for headquarters, command units and others who decide about actions before, during and after some emergency situations. Few decades ago, GIS was the expensive technology because it was new on the market and with high price inaccessible to many. Also, there was limitation from producer that only scientific institutions and military institutes could use GIS. Many years later, it was clear that GIS should be used in many areas and this technology has become accessible to all. Today, GIS technology makes a very huge turnover which can be counted with many billions of euros. This information system is part of lessons at many famous and important schools and colleges. Today, all the institutions and companies that work with space data and management and exploitation of spatial objects, use GIS. The examples of previous sentence are urbanism, construction land, road and rail networks, water supply, sewerage, electricity, gas distribution, telecommunications, heating, ecology, green, agriculture and forestry, etc. As noted areas, responsible institutions for emergency management recognize GIS and use it in all phases.

\section{PREPAREDNESS FOR EMERGENCY SITUATIONS AND GIS}

As mentioned in the previous part of this paper, emergency management has four phases in the function cycle. Preparedness is the first one. During this period, responsible institutions have a task to prepare citizens, schools, companies, and all protected values for possible emergency situations. This phase compared with others, consumes a lot of time and money. Usually, many forget about the importance of implemented actions in order of prevention and preparedness. Only one dollar invested in prevention can save up to seven dollars of economic loss (UNDP, 2012).

Emergency management programs begin with identifying potential emergency risks. Using a GIS, officials can pinpoint hazards and begin to evaluate the consequences of potential emergencies or disasters. When hazards, such as earthquake faults, fire hazard areas, flood zones, shoreline exposure and others are viewed with other map data (streets, pipelines, buildings, residential areas, power lines, storage facilities, etc.), emergency management officials can begin to formulate mitigation, response, and possible recovery needs (Johnson, 2000). An appropriate plan is very important for mitigation, response and recovery. The process of emergency planning during the phase of preparedness is not so easy. GIS facilitates this process by providing planners opportunity to view the spatial data generated at computer maps

During the phase of preparedness emergency management bodies at all levels, from local to national, have to make some documents which are very important. Risk assessment and emergency plan are two of them. By risk assessment, all institutions included in emergency management cycle provide necessary analyzes about potential risk form natural and other disasters. This document should prevent potential hazards that threaten citizens and other protected values. GIS is the useful tool for making adequate risk assessment. Maps can show the critical points and development of some emergency. For example, space which will be flooded on GIS platforms can be connected with information about density of population, number of objects in that area, number of children, and all necessary data important for somebody who will make decision when flood occur. On the other side, emergency planning and plan, as a final result of this process, are very important parts of the first phase for emergency management. In this document, based on the previous-risk assessment, emergency management representatives have to elaborate on what will be done in other phases. This is not a simple job and without serious approach it will not give the desired result. So, GIS should be used for planning to show all actions which define plan. Emergency management planning requires acquiring, integrating, and analyzing vast amounts of information and data in a variety of disparate formats to develop a comprehensive risk-based emergency management program. First, GIS optimizes the planning process because by it we can identify and map natural and technological hazards, identify and map critical values at risk or identify values at risk that reside within the impacted areas of natural or technological hazards (ESRI, 2008). GIS is used for modeling of different scenario which have possibility to become real. Loses can also be projected. Priorities for emergency response are mentioned through the use of GIS.

Education is also an the important part of preparedness for emergency situations. Today, everybody needs basic knowledge on how to react in eventually dangerous situation, caused by natural or other disasters. Modern information technologies give huge offer how to create education programs and materials. On the other side, sentence that "A picture is worth a thousand words" (Bouch, 2009) is very popular and for sure will justify use of GIS maps in new education materials. Printed lectures, brochures or similar, should have GIS outputs. People who will use these materials will make the picture in their heads about "circle of dangerous", after chemical accident in some 
factory or after floods. So, they will learn more effectively than before, when is used only the lectures based on text.

\section{MITIGATION OF EMERGENCY SITUATION AND GIS}

Before emergency situation starts, emergency management bodies need to take the appropriate action to mitigate the effects that will happen. So, the next phase immediately before emergency situations is called mitigation. In the this phase, governments, organizations, and individuals develop plans to save lives and minimize disaster damage (for example, compiling state resource inventories, mounting training exercises, installing early warning systems, and preparing predetermined emergency response forces) (Johnson, 2000). By mitigation measures, we want to enhance future disaster response actions. For example, this means checking stock of vital food and medical supplies, training exercises and by mobilizing special emergency units on standby.

GIS is the powerful tool for this phase. This technology can provide answers to the following questions, such as:

- How many paramedic units are required and where should they be located?

- What evacuation routes should be selected if a toxic cloud or plume is accidentally released from a plant or storage facility based on different wind patterns?

- How will people be notified?

- Will the road networks handle the traffic?

- What facilities will provide evacuation shelters?

- What quantity of supplies, bed space, and so forth, will be required at each shelter based on the number of expected evacuees? (Johnson, 2000)

In this phase, we can use GIS also to show on maps all inputs received from institutions responsible to monitor environment situations such as hidro-meteorogical agency, seismological agency or similar. The mentioned institutions provide necessary information for local or national emergency management bodies, which later make warnings important in mitigation phase. This warning is usually public and should be viewed via the Internet or television. GIS can display real-time monitoring for emergency early warning. Earth movements (earthquake), reservoir level at dam sights, radiation monitors, and so forth, can all be monitored and displayed by location in GIS (Johnson, 2000). The use of GIS enables it to deliver this type of information and geographic display over the Internet for public information.

\section{USING GIS IN RESPONSE TO EMERGENCY SITUATIONS}

Probably the most important and complex phase of emergency management is response. During this phase, responsible emergency institutions have a wide range of tasks to save and rescue people, and protect environmental and heritage values. This phase consist of unified answer of different subjects as fire and rescue units, hospitals and other medical institutions, Red Cross, army and similar. So, coordination is very important as it provides instructions on how to use resources in the most effective way.

To achieve goals of this phase, it is necessary to use information technologies, such as GIS. The name for centers, where information about emergencies is gathered, processed and dispatched, should be different. We can call them with one name which shows their main function. This name is Emergency Operations Center which is responsible for supporting incident management operation needs and maintaining continuity of operations for the community. Acquiring, managing, and maintaining status of resources from various locations is an important function (ESRI, 2008). To centers is coming information from court. People who work in these centers are responsible for their analysis, making priorities for rescue operations and making of reports for different users. More important is one report with maps, showing the affected areas, the nearest shelters and firefighter units. This reports are a helpful tool for decision makers and they would enable the to make the appropriate decisions in a timely manner. There are also few functions which GIS can provide in the response missions such as:

- Provide warnings and notifications to the public based on the location or areas to be impacted by the incident,

- Maintain shelter location continuity of operations: supply inventories, external power requirements, shelter population capacities,

- Support incident management operations and personnel, provide required resources, and exchange internal and external information,

- Prepare maps, briefs, and status reports for the executive leadership (elected officials) of the jurisdiction (ESRI, 2008).

Natural and other disasters which affect a lot of people and make big damages require a huge number of different resources. For example, floods which occurred on the territory of the Republic of Serbia in mid-May 2014 affected a large area and Serbia suffered great damage with human 
casualties. Response phase was very complex, because it was big catastrophe. A lot of people and material resources were necessary to provide an answer. Also, this emergency situation was characterized by scattered flooded places. This requires adequate resource dispatching. In situation as this, especially when resources are limited, GIS is the powerful tool for proper schedule of resources. GIS can provide one of the primary components for computeraided dispatch systems. Emergency response units based at fixed locations can be selected and routed for emergency response. The closest (quickest) response units can be selected, routed, and dispatched to an emergency once the location is known (Johnson, 2000). So, institutions responsible for emergency response will have the opportunity to avoid mistake and not to overload one place with recourses, and on the other not to have enough. GIS maps give the chance to consider where and which recourses should be dispatched. Also, the evacuation is one task which is usually realized during the response phase. On GIS platforms we can see and after decide which route is most safety for evacuation of people, animals or cultural values. In case of earthquake, floods and other risks, it is not easy to decide where is safety to conduct evacuation. For example, earthquakes may have repeated shock and that consequence can affect evacuation direction.

Modern GIS technologies provide more opportunities that can contribute to better emergency response. One example for this is the advanced vehicle locating which can be incorporated to track (in real time) the location of incoming emergency units. This locating can also assist in determining the closest mobile units to be dispatched to an emergency, as they are located on the map through global positioning system transponders (Johnson, 2000). So, on one map can be shown all dispatched units, their movement and change of location to another affected territory.
Situational awareness for emergency management personnel is very important to provide the right answer. Situational awareness means to be aware of what is happening around and possible consequences of natural or other disasters. This is especially important where situation is very serious and threatens to make much greater damage. GIS provides situational awareness through high operating maps. Maps can display relevant GIS data as critical infrastructure or hazards integrated with dynamic event data collected from sensors, cameras, traffic escorts to represent the current situation. Only by comprehensive situational awareness, emergency management personnel will have an opportunity to make better decisions that after can be shared, and understood by units which have to take actions. In order to enhance situational awareness during the response phase to maps can also be added the response plans or contingency plans, and other documents.

Based on the previous text, it can be concluded that GIS plays a great importance during the response phase. With this technology is much easier to make the right answer, save people's lives and protect material and cultural assets.

\section{RECOVERY FROM EMERGENCY SITUATION AND GIS}

Recovery efforts begin when the emergency is over (immediate threat to life, property, and the environment). Recovery efforts are often in two phases, short term and long term (Johnson, 2000). The short term recovery is focused on the essential needs of citizens who were affected by emergency situations. That primarily means water purification, energy supplying, telecommunications, healthy institutions and similar. On the other side, actions which
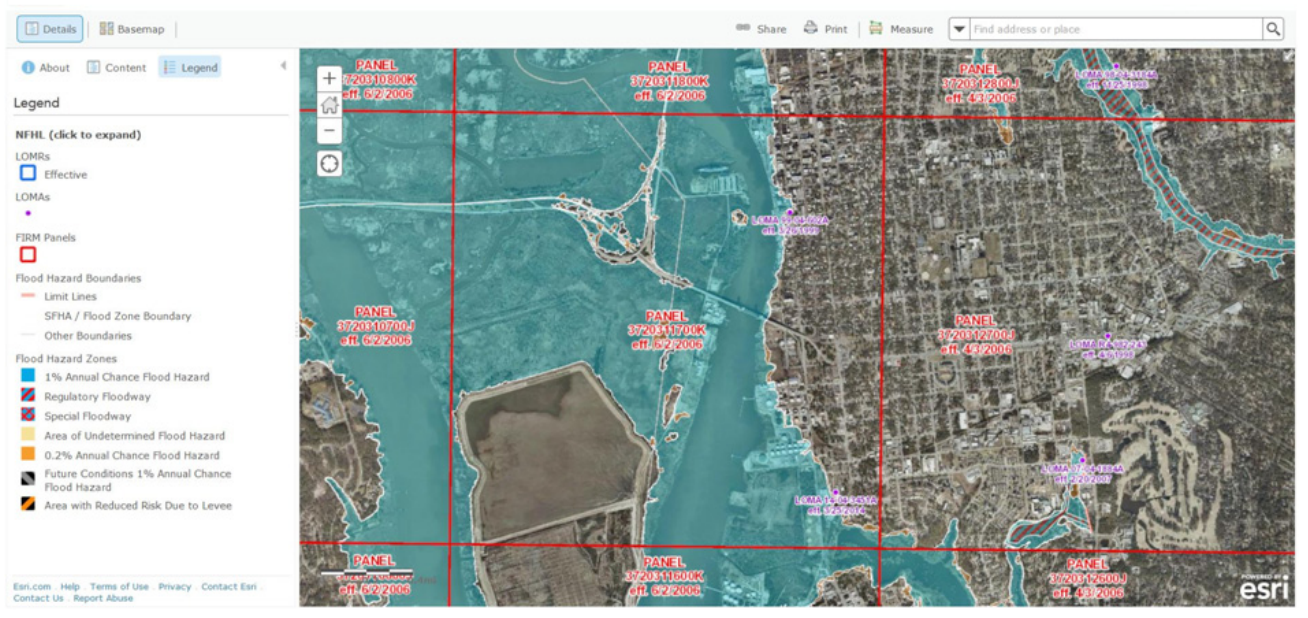

Figure 1. Example of GIS map in case of flood response (FEMA,2015) 
are taken during long term recovery are focused on business entities, educational institutions and similar. In both phases, we can use GIS, as a the helpful tool to bring all living conditions into normal state.

After emergency situations, people's basic needs have to be satisfied as soon as possible. Priorities must be made and responsible institutions start to work on mentioned tasks in short recovery phase. It is not simply job because of many problems that occur immediately after the end of emergency situations. One very important task is to make the appropriate assessment, determine what happened and where to start with recovery. Using GIS, decision makers will have the precise picture of the source of problem. GIS can locate each damaged property, identify the amount of consequences, and begin to establish the first places for immediately actions. Also, when emergency situations start, GIS use one database. In recovery phase the situation is probably completely different. So, especially in short term recovery phase, this database has to be updated. Also, after most of natural or other disasters people should be in shelters, temporarily or permanently. They have to be there until the conditions in their houses are not same as before the emergency situation. With adequate database, GIS will show the location of shelters, number of people in them and their essential needs (food, water...).

After short term recovery phase starts long term recovery phase. As stated in the previous text, during this period is important to think how to employ people who lost job because of emergency situation. The part of this phase is also critical infrastructure, such as roads, bridges, etc. Everything has to be in normal or better conditions. Long term recovery is characterized by huge investments. For recovering of one bridge, the responsible institution has to pay a lot of money, probably in millions of euro. GIS provides the opportunity to show on one place the progress of investments. The investors, who are usually country governments or donors from abroad, want to check at any moment this progress. They can see on GIS maps which task is finished and where are bottlenecks.

\section{EXAMPLES OF GOOD PRACTICE OF USING GIS}

Institutions, responsible for emergency management, in many countries use GIS in all the mentioned phases. They have recognized all values of GIS in practical activities.

United States Army Corps of Engineers has the mission to deliver vital public and military engineering services, partnering in peace and war to strengthen their nation's security, energize the economy and reduce risks from disasters (US Army Corps of Engineers, 2001). Besides the main orientation to investigation in the area of military activities, this organization tries to pay more attention to develop and use modern technologies for emergency management. One example of this is the GIS. They use GIS for different tasks, such as gap analysis, capability assessments and public affairs. Gap analysis, which is realized with the GIS, can facilitate data collection and acquisition prioritization. When emergency situation occur, this organization use GIS to work on capability assessments. They use geospatial data as a tool to determine organizational strengths and weaknesses. This is especially important for subjects that are involved in national search and rescue system. In the area of public affairs, United States Army Corps of Engineers use GIS to

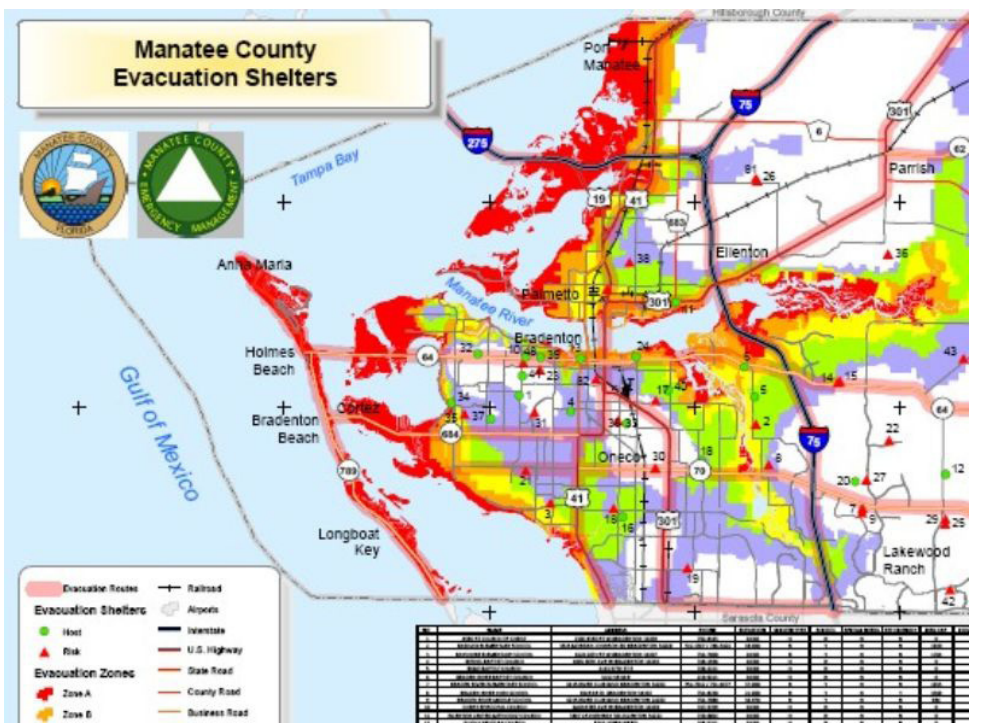

Figure 2. A sample of the evacuation shelter map (from https://www.mymanatee.org, Retrieved March 27, 2016) 
disseminate geospatial information, such as static maps and prepared data for web viewers and social media.

In mid-May 2014, the Republic of Serbia experienced the worst flood in over 100 years. The extreme floods had been caused by heavy rainfall during three days. National capacities were not enough to answer on this situation. Many teams came from abroad to help Serbian's authorities. United Nations Disaster Assessment and Coordination (UNDAC) Team was deployed to Serbia. Two mapping and GIS experts from MapAction were attached to the UNDAC Team (OCHA, 2014). Use of GIS during floods was very significant. GIS maps, prepared by Serbian's Sector for Emergency Management and international team, were used for different tasks. Flooded areas and forecasts of the movement of the flood wave were presented on maps. This was the useful tool for decision makers, who were responsible to decide about the evacuation routes, care places for evacuated people, etc.

\section{CONCLUSION}

GIS, as a system, is a very powerful tool for emergency management decision makers during all four phases. Regardless of preparedness, mitigation, response or recovery, GIS will find its place. Responsible institutions must have this in their operating centers. If they do not have, they must start to think about that.

Also, because GIS primarily depends on information, this information system is good provided that information is adequate. So, decision makers in the area of emergency management should be cautious. GIS will not provide the appropriate maps and other products if database is not correct. Also, for all phases, it is characteristic that they are very dynamic and unpredictable. For example, during preparedness phase, some buildings or bridges are built and new forests are planted. Everything has to be included in GIS platforms in order for the final GIS product to be adequate for users. It is not an easy process, especially during the response phase. Coordination between somebody who is in charge for GIS and other stakeholders who are obliged to give data is very important. Without this, we will have incorrect data and final maps will show false picture. Consequences may be catastrophic, especially because in this case attention is placed on people's lives, animals and cultural and other heritage.

On the other side, GIS invest constant efforts to make innovations. Today, the most of people use mobile phones. This technology has found its role in emergency management. Communication between citizens, operating centers and first responders goes through mobile phones. Also, the first responders use other technolo- gies, such as TETRA for example. But, citizens who are in danger from natural or other disasters probably will call the operating center by mobile phone. GIS producers now try to make option for this information system to automatically show the caller's location and display on GIS maps. As the calls come in, the system automatically displays caller's location on a map, and dispatchers who use the same map will see which emergency units are in the best position to respond. Dispatchers can also see which fire stations are nearby, enabling them to send units equipped to deal with hazmat situations. The maps, enriched with several layers of GIS data, also show the nearest hospitals from which to dispatch emergency units (European emergency number association, 2015).

With new options, GIS will undoubtedly be an information tool necessary in any emergency management institution.

\section{REFERENCES}

Bouch,J. (2009). A picture is worth a thousand words. Advances in Psychiatric Treatment. Vol.15, 81. Retrieved March 10, 2016 from The Royal College of Psychiatrists database on the World Wide Web: http:// http://apt.rcpsych.org/content/15/2/8. DOI: 10.1192/apt.15.2.81.

Environmental Systems Research Institute. (2008). Geographic Information Systems Providing the Platform for Comprehensive Emergency Management. Environmental Systems Research Institute White Paper. Retrieved March 10, 2016, from http:// www.esri.com

European Emergency number association. (2015). Using and optimizing GIS in an emergency response. European Emergency number association - EENA Operations Document. Retrieved March 02, 2016, from http://www.eena.org

Johnson,R. (2000). GIS Technology for Disasters and Emergency Management. Environmental Systems Research Institute. Retrieved March 10, 2016, from http:// www.esri.com

United Nations Development Programme. (2012). Putting resilience at the heart of development - Investing in Prevention and Resilient Recovery. UNDP Representative Office in Japan. Retrieved March 04, 2016, from http://www.undp.or.jp

United Nations Disaster Assessment and Coordination Team. (2012). End of mission report. OCHA. Retrieved April 20, 2016, from https://www.humanitarianresponse.info

US Army Corps of Engineers. (2001). Geotechnical Investigations. Engineering and Design. Retrieved April 20, 2016, from http://www.publications.usace.army.mil 